\title{
INFLAÇÃO E POLÍTICA NO BRASIL CONTEMPORÂNEO: A EXPERIÊNCIA DOS GOVERNOS FHC E LULA
}

\author{
INFLATION AND POLICY IN BRAZIL CONTEMPORARY: \\ THE EXPERIENCE OF FHC AND LULA GOVERNMENTS
}

José Carlos Martines Belieiro Junior*

RESUMO: O objetivo do trabalho é analisar a relação entre a inflação e a política no período de redemocratização sob os governos FHC e Lula. A motivação principal é busca da dimensão política dos fenômenos econômicos, e da inter-relação entre política e economia. A inflação foi a principal questão política dos governos democráticos entre 1985-1994. Muitos planos de estabilização foram tentados e apenas o Plano Real conseguiu debelar a inflação alta no Brasil. Os governos FHC e Lula foram marcados pela estabilidade econômica, mas a inflação ocupou um lugar relevante na agenda política dos dois governos e as políticas voltadas à estabilidade da inflação prejudicaram o crescimento econômico sob os governos democráticos. $\mathrm{O}$ trabalho procura analisar essas questões sob o ponto de vista político, incorporando a dimensão econômica no processo de redemocratização política no Brasil. O trabalho analisa os percalços da transição democrática nos governos Sarney e Collor, com uma ênfase especial à experiência dos governos FHC e Lula.

Palavras-chave: inflação; democracia; política econômica; governo FHC, governo Lula

\footnotetext{
* Doutor em Sociologia; Professor no Departamento de Ciências Sociais e no Programa de PósGraduação em Ciências Sociais da Universidade Federal de Santa Maria - UFSM, Santa Maria, RS, Brasil; e-mail: jcmbjunior@yahoo.com.br

182| Século XXI, Revista de Ciências Sociais, v.3, nº 2, p.182-212, jul./dez. 2013 ISSN: 2236-6725
} 
ABSTRACT: The objective is to analyze the relationship between inflation and political democratization in the period under the FHC and Lula. The main motivation is the pursuit of the political dimension of economic phenomena, and the interrelationship between politics and economics. Inflation was the main political issue of democratic governments between 1985-1994. Many stabilization plans were attempted and only the Real Plan succeeded in overcoming the high inflation in Brazil. The FHC and Lula were marked by economic stability, but inflation has occupied an important place on the political agenda of both governments and policies concerning the stability of inflation hindered economic growth under democratic governments. The paper analyzes these issues from the political point of view, incorporating the economic dimension in the process of political democratization in Brazil. The paper analyzes the drawbacks of democratic transition in the Sarney and Collor, with a special emphasis on the experience of the FHC and Lula.

Keywords: inflation; democracy; political economy; FHC governement; Lula governement.

\section{INTRODUÇÃO: A QUESTÃO DA INFLAÇÃO NA TRANSI- ÇÃO DEMOCRÁTICA}

A economia e a sociedade brasileira viveram uma dramática experiência de inflação alta que perdurou por quase duas décadas. Desde o final do regime militar em 1979 até meados de 1994, o índice total de inflação havia atingido os impressionantes 13.342.346.717.617,70\% colocando o país na pior crise econômica de sua história republicana. Os anos de inflação alta e descontrolada acompanharam todo o processo de redemocratização política, atingindo diretamente os governos democráticos: governo Sarney (1985-1990), governo Collor (1990-1992) e governo Itamar (19921994), mobilizando 13 diferentes ministros da fazenda, 6 diferentes moedas, 9 zeros cortados e finalmente, 5 planos de estabilização econômica tentados. 
A inflação alta foi finalmente controlada pelo Plano Real em 1994 e os governos FHC e Lula conviveram com taxas comparativamente baixas quando se observa o comportamento dos preços nas décadas de 80 e 90 . Desse modo, enquanto os primeiros governos da redemocratização (1985-1995) conviveram com alta inflação e instabilidade econômica permanente, os governos FHC e Lula conseguiram atravessar dois governos consecutivos cada (1 ${ }^{\circ}$ FHC-1994-98 e $2^{\circ}$ FHC -1998-2002) e (1 $1^{\circ}$ Lula 2002-2006 e $2^{\circ}$ Lula - 2006-2010), sob uma ordem econômica mais estável em termos de política de controle de preços. No entanto, isso não significa afirmar que mesmo sob a inflação baixa e sob controle da política econômica do Real adotada a partir de 1994, e continuada em 2003 em diante, que a inflação tenha deixado de ser um problema econômico, político e social para os governos FHC e Lula. Ao contrário, a questão da inflação permaneceu presente nos dois governos analisados, como se pretende demonstrar nos limites desse artigo.

O objetivo deste trabalho é justamente analisar a relação entre inflação e política, ou seja, entre esfera econômica e esfera política tendo como perspectiva de análise, entender o sentido político que inflação assumiu nos governos FHC e Lula. A ideia que orienta esse trabalho é a procura de uma análise integrada entre economia e política, buscando compreender a dinâmica da transição democrática a partir da problemática da dimensão econômica, nesse caso, a inflação. Grande parte dos argumentos desenvolvidos no âmbito deste trabalho são beneficiados por trabalhos anteriores de economia e política, como os de Sola (1988) e (1993), Sallum Jr. e Kugelmas (1993) e Sallum Jr.(1996) e (1998). Outros trabalhos enfatizam os aspectos técnicos da inflação, especialmente os trabalhos de economistas. Nesse aspecto, os trabalhos são abundantes e nos servem de importante referência. Entretanto, o objetivo é procurar entender os impactos da inflação na esfera política, entendo a inflação como uma questão política.

O trabalho esta organizado do seguinte modo: na introdução, procura-se fazer uma análise introdutória sobre a inflação no período da redemocratização, sob os governos Sarney, Collor e Itamar Franco. Depois, nos itens seguintes, uma análise do problema da 
inflação no governo FHC, no governo Lula e, finalmente, as conclusões finais. Adota-se aqui a idéia de inflação acumulada como parâmetro para compreender o tamanho da problemática inflacionária enfrentada pelos governos da transição democrática.

Embora a dinâmica e o comportamento da inflação nos governos FHC e Lula tenham de fato, se mantido baixos, é indispensável considerar que mesmo sob um regime de inflação controlada, os impactos econômicos, sociais e políticos ainda são relevantes para o bom entendimento dessas experiências de governo, além de uma importante maneira de se entender os limites e contradições da política econômica dos governos democráticos de FHC e Lula. Em outros termos, o artigo se propõe a entender as conseqüências da política econômica adotada nos governos FHC e Lula do ponto de vista político. Por isso, a idéia básica que orienta a análise é explorar as relações entre esfera econômica e esfera política, tendo como perspectiva central a posição ocupada pela inflação na política brasileira contemporânea.

Durante todo o processo de redemocratização política do país - momento de enorme expectativa social quanto à construção de um novo regime político democrático - foi inegavelmente marcado pela presença da inflação alta. O primeiro governo civil da transição, o governo Sarney foi obrigado a adotar 3 diferentes planos de estabilização econômica. O primeiro foi o Plano Cruzado, lançado em fevereiro de 1986, seguido pelo Plano Bresser de junho de 1987 e o Plano Verão, lançado em janeiro de 1989. Todos os três planos de estabilização da economia fracassaram no objetivo de controlar a inflação e promover maior crescimento econômico e a política econômica do governo Sarney oscilou entre o experimentalismo heterodoxo do Plano Cruzado ao retorno ortodoxo do Plano Verão. Do ponto de vista político, a inflação adquiriu enorme importância nos governos dos anos 80 e 90. Toda a dinâmica da popularidade presidencial e o sucesso ou o insucesso político do governo em questão deveria passar obrigatoriamente pelo controle definitivo dos preços. Em contexto de inflação alta como foi a inflação dos anos 1985-1994, seria impossível governar a sociedade e a economia brasileira e a própria posição do Estado como monopólio do poder sobre a sociedade, se enfraquece. 
Durante o governo José Sarney, o primeiro governo civil depois de 1964, a sua popularidade e aceitação popular ao seu mandato presidencial ficaram atreladas ao sucesso da política de controle da inflação. Sob inspiração da teoria da inflação inercial - uma novidade no campo da teoria econômica sobre a inflação - o Plano Cruzado obteve grandes dividendos políticos e o partido do Presidente Sarney conseguiu vencer as eleições para governadores estaduais em praticamente todos os Estados do país no pleito de 1986, quando o PMDB se consagrava o maior partido político brasileiro. Ao mesmo tempo, nos meses em que o Plano Cruzado parecia funcionar bem sucedidamente, Sarney tornava-se símbolo da cidadania de consumo popular obtida através da política de congelamento de preços, umas das principais medidas do Cruzado. Entre os meses de fevereiro a junho, experimentou-se um período de verdadeira lua de mel do presidente Sarney com a sociedade brasileira, com os preços sob vigilância de todos e consumo ampliado pela valorização dos salários (Singer, 1987).

Pode-se afirmar que a inflação alta e descontrolada dos anos 80 combinada com a necessidade do governo se legitimar politicamente perante a sociedade brasileira, levou a iniciativas de um político de origem conservadora como José Sarney a adotar medidas inovadoras e radicais de política econômica como forma de obter legitimidade política. A inovação se refere a adesão do governo Sarney ao projeto de combate à inflação inercialista e heterodoxo dos economistas formuladores da teoria da inflação inercial (Arida, 1986), (Lopes, 1988), (Sardemberg, 1987) e (Bier, Paulani, Messenberg, 1987). O Plano Cruzado foi para o governo de José Sarney a principal tentativa de um só tempo, controlar a economia e a política num cenário em profunda crise econômica e política.

A crise do governo Sarney e a fragmentação do campo governista e oposicionista nas eleições de 1989 foram causadas pelo insucesso do governo em controlar a inflação alta. A inflação acumulada durante seu mandato foi de impressionantes 3.638, 43\%, um índice ainda pior quando iniciou seu mandato presidencial. $\mathrm{Na}$ época das eleições presidenciais diretas, a primeira eleição desde 1960, a inflação brasileira estava na casa dos $80 \%$ ao mês. Durante as eleições 
de 1989, foram lançadas 21 candidaturas à Presidência da República, desde Ulysses Guimarães pelo partido do governo, o PMDB, passando por Collor do PRN, Brizola pelo PDT e Lula pelo PT. O candidato do recém fundado PSDB era Mario Covas que depois veio a ocupar o governo do Estado de São Paulo nos anos FHC. A crise política deflagrada pela crise econômica e inflacionária dos anos 80 facilitou a eleição do estreante Fernando Collor à Presidência da República nas eleições de 1989. Embora nem Lula e nem Collor tenham deixado claro como acabariam com a inflação, o fato é que nem a esquerda representada por Lula e a direita representada por Collor mostraram com clareza na campanha daquele ano, os seus respectivos projetos de política econômica e de combate à inflação. O contexto político e eleitoral do final dos anos 80 era de grande incerteza quanto ao enfrentamento da inflação no Brasil.

Com a vitória eleitoral de Collor sobre Lula no segundo turno das eleições presidenciais de 1989, obtendo cerca de 35 milhões de votos, a primeira medida do seu governo foi o anúncio das medidas do chamado Plano Collor, lançado em março de 1990. Novamente, foram adotadas medidas radicais e heterodoxas para vencer a inércia inflacionária, dentre elas, o confisco dos depósitos em poupança, o congelamento de preços, uma nova reforma monetária e uma nova moeda, o Cruzeiro. O plano foi lançado e implementado sem qualquer consulta ao Congresso Nacional e os partidos políticos e/ ou entidades representativas da sociedade, num estilo eminentemente autoritário e personalista da gestão Collor. Consagrou-se naquele contexto o estilo cesarista do governo Collor, numa tentativa de resolver os graves problemas econômicos a partir de cima das instituições políticas, uma espécie de ação direta do Estado em atacar a crise (Bresser-Pereira, 1991).

Pode-se afirmar que o desespero dos governos da transição democrática em controlar definitivamente o problema da inflação alta produziu uma dinâmica de medidas heterodoxas e radicais, como o Plano Cruzado e o Plano Collor, que foram planos de estabilização concebidos a partir do Estado sem qualquer mediação política e institucional. Medidas consideradas milagrosas, elaboradas por uma 
equipe econômica dotada de capacidade quase onipotente para lidar com os problemas do país, muitas vezes, essas medidas causavam ainda mais pânico e incerteza na sociedade do que propriamente uma solução definitiva para o problema da inflação alta e descontrolada. A aplicação da política econômica deve estar vinculada a dinâmica política do regime democrático, o que também acaba por dificultar a sua implantação (Sola, 1988). Por ouro lado, a inflação alta obrigava os governos da transição democrática a adotarem medidas ortodoxas e impopulares, aprofundando a recessão econômica, como aconteceu com o governo Collor, onde nos anos 1990-92, a inflação acumulada foi de $3.212,74 \%$ e desempenho de $-3,86 \%$ de PIB.

O fracasso do Plano Collor com todo seu radicalismo heterodoxo de medidas anti-inflacionárias durou pouco tempo e logo no ano seguinte, em 1991, outro plano de estabilização foi lançado, o Plano Collor II, de orientação ortodoxa que também acabou fracassando na luta contra a inflação. A incapacidade do Governo Collor em acabar de vez com o problema da inflação certamente colaborou na deflagração da crise política que levou ao seu impeachment em setembro de 1992. Embora a razão principal da perda do seu mandato tenha sido causada por denúncias de corrupção e tráfico de influência (Conti, 1999), o período Collor é um dos períodos de maior inflação do período democrático, em apenas dois anos a inflação acumulada quase equivale aos cinco anos de Sarney no poder. (ver quadro) Se Collor fracassou na luta contra a inflação, de outro lado, seu maior êxito foi acreditar que a abertura econômica e as medidas de reforma liberal, como as privatizações de empresas estatais e a reforma do Estado, devolveriam um ciclo de crescimento econômico e melhoria nas condições sociais, mas, o governo Collor obteve sucesso relativo nesse campo. Caso o Governo Collor conseguisse atingir seu objetivo principal na luta contra a inflação, seu projeto político de reformas liberais teria atingido outro patamar.

O Governo Itamar Franco (1992-94) surgiu na esteira da crise política e inflacionária do governo Fernando Collor. Assim como em outros diferentes contextos de incerteza da transição democrática, a missão de seu governo era tentar produzir estabilidade econômica 
num ambiente político difícil e de baixa legitimidade. Novamente, a história parecia se repetir com Itamar, vice de Collor na chapa de 1989, na curta experiência da transição democrática, entre 1986-92, um vice-presidente toma o lugar do titular, como foi com Sarney diante da morte inesperada de Tancredo Neves. E mais uma vez, os desafios eram enormes para Itamar Franco: a busca pela estabilidade econômica como forma para obter legitimidade política entre a sociedade brasileira e os grupos políticos relevantes. Entretanto, diferentemente de outros governos, Itamar não adotou medidas radicais de urgência, com um novo plano de estabilização. Sua gestão foi marcada por grande instabilidade econômica, com variações na política econômica e seis diferentes Ministros da Fazenda em menos de dois anos de mandato. Mas ao mesmo tempo, procurou pavimentar o caminho para a elaboração de um novo plano de estabilização que foi o Plano URV/Real, lançado em junho de 1993, obtendo finalmente êxito no combate à inflação.

Desse modo, como se pode perceber, os governos da primeira geração da transição democrática, que compreende os anos 1985-1994, ou seja, os governos Sarney, Collor e Itamar Franco, foram obrigados a conviver com uma conjuntura de instabilidade econômica permanente e a persistência da inflação alta e descontrolada. Para tentar alcançar o objetivo de uma economia sem inflação como condição si ne qua non para a estabilização política, esses governos foram obrigados a adotar medidas heterodoxas e ortodoxas que produziram mais instabilidade, inflação e perda de apoio e legitimidade política, aprofundando a crise política do Estado brasileiro. Nesse sentido, a inflação alta e o desempenho da economia nos anos 85-94 apontam para um fracasso dos primeiros governos democráticos em vencer a inflação e levar o país para um novo ciclo de crescimento e desenvolvimento. A inflação descontrolada significou para esses governos um pesadelo constante, na medida em que os critérios econômicos passaram a condicionar a avaliação de um bom desempenho governamental. E os governos democráticos da primeira geração amargam a pior inflação registrada em toda a história do Brasil, na soma dos governos Sarney, Collor e Itamar, a inflação acumulada foi de $10.244,75 \%$. 


\section{O GOVERNO FHC}

O governo Itamar Franco (1992-94) pode ser considerado de transição entre a situação de inflação alta e descontrolada para uma situação de inflação baixa e sob controle. A própria estratégia política que levaria o sociólogo Fernando Henrique Cardoso ao poder nas eleições de 1994 seria gestada no interior do governo Itamar Franco, quando FHC foi convidado para ocupar o Ministério da Fazenda em 1993. Nesse aspecto, é importante considerar que a sustentação da candidatura de FHC à Presidência no interior da coalizão política por ele liderada, teve na luta contra a inflação o seu maior trunfo político e pessoal. Isso é relevante considerar porquê foi na condição de Ministro da Fazenda de Itamar que FHC pode formatar entre políticos e economistas inercialistas a concepção programática e política que levaria ao Plano Real. (Toledo, 1998).

Mais uma vez, a prioridade para o grupo político de FHC que compunha o apoio partidário no interior do governo Itamar era o combate definitivo da inflação. A própria viabilidade eleitoral da candidatura FHC passaria obrigatoriamente pelo sucesso da estratégia do Plano URV/Real, afinal, novamente o enfrentamento eleitoral de 1994 seria entre duas candidaturas polarizadas, uma a esquerda liderada pelo PT de Lula e a outra de centro-direita, liderada pela coalizão PSDB-PFL. A experiência política de FHC adquirida na luta política anti-inflacionária dos tempos do Plano Cruzado, quando FHC era líder do governo Sarney no Senado, foi extremamente importante para seu sucesso posterior. O sucesso de FHC com o plano de estabilização econômica seria o passaporte para seu sucesso eleitoral como candidato da aliança política gestada no interior do bloco governista de Itamar Franco.

Como bem demonstrou Carlos Pio (2001), a rede formada pelo grupo de economistas inercialistas, estabelecidas no contexto dramático do Plano Cruzado foi o elemento diferencial que atuou a favor de FHC no momento da formulação do Plano Real. Nesse sentido, foi a experiência política na luta contra inflação nos anos 80 que ajudou FHC a liderar de modo bem sucedido a luta política no âmbito do 
Plano Real nos anos 90. A sua habilidade política em lidar com os políticos no interior do Congresso Nacional e os partidos políticos, bem como a sua habilidade pessoal em lidar com os principais economistas da rede heterodoxa e inercialista foi de fato, o ingrediente central da estratégia bem sucedida que produziu o Plano Real.

Essa experiência política FHC adquiriu no interior do Estado parlamentar, uma vez que FHC vinha atuando politicamente desde o final do regime militar-autoritário no partido político PMDB e na intensa luta parlamentar. Em 1986, em dissidência direta com o governador paulista Orestes Quércia, FHC e outros, fundaram o PSDB (Partido da Social-Democracia Brasileira).

Nas eleições presidenciais de 1994, a inflação e a crise econômica foram um dos principais temas de campanha para os dois candidatos, Lula novamente pelo PT e FHC pela aliança PSDB e PFL. O candidato petista convocara inclusive um economista assessor econômico do partido, o ex-professor da PUC-SP Aloísio Mercadante, para debater com mais competência os temas econômicos e principalmente a inflação. As chances de uma vitória eleitoral de Lula eram reais, havia o acúmulo dos de 29 milhões de votos do pleito de 1989 e um contexto político menos fragmentado e radicalizado como foi o embate com Fernando Collor. Novamente, como em 89, havia o medo do custo Lula e de suas posturas radicais diante da economia e da própria inflação, visto que durante a campanha, a posição de Lula diante do plano de estabilização recém lançado era uma grande dúvida entre o empresariado e os mercados. Lula manteve-se na dianteira das eleições de 1994 até o mês de julho de 1994 quando entre em vigor a nova moeda, o Real, e a inflação começa a cair para níveis extremante baixos.

Naquele importante mês de 1994, ocorre um cruzamento dos gráficos de intenção de voto, ou seja, enquanto a inflação caía, o desempenho eleitoral de FHC subia e ajudava a melhorar sua posição nas pesquisas de intenção de voto. A queda da inflação e o sucesso do Real tiveram impacto imediato no comportamento eleitoral, ou seja, sua candidatura crescia na medida exata em que a inflação despencava, e as variáveis econômicas se encaixavam com as variáveis eleitorais, numa 
demonstração da força da economia nas eleições (BORSANI, 2003). Entretanto, apesar da conjuntura favorável, FHC também encontrou dificuldades para sua eleição à Presidência. FHC era um intelectual pouco conhecido do grande eleitorado nacional e havia disputado apenas a eleição para prefeitura de São Paulo em 1986, ocasião em que foi derrotado para um político populista tradicional, Janio Quadros.

Mas FHC procurou fazer sua campanha explicando a política do Real para a sociedade brasileira. Nesse sentido, foi a luta política contra a inflação travada na experiência dos governos dos anos 80 e 90 que fez de FHC um político viável e experiente para ganhar as eleições presidenciais de 1994. Em resumo, foi à luta contra a inflação que ajudou a qualificar FHC para assumir o posto máximo de poder político do país.

Assim, pode-se facilmente afirmar que o sucesso imediato do Plano Real no combate a inflação ajudou decisivamente a eleger FHC nas eleições de 1994. Em 1998, diante de uma situação econômica conjuntural diferente daquela de 1994, a vitória de FHC na reeleição pode ser creditada aos ganhos relativos proporcionados pela estabilidade inflacionária e em grande medida, pela política de paridade cambial adotada pelo governo em 1994, responsável pela difusão de ganhos econômicos e sociais dos anos 94-98. Dessa forma, indiretamente foi a inflação que produziu FHC presidente da República por oito anos no Brasil. De outro lado, pode-se considerar que as derrotas de Lula do PT nos pleitos de 1994 e 1998 se devem basicamente a indefinição do Partido dos Trabalhadores em lidar com o problema da inflação e na dificuldade do partido apresentar um projeto alternativo de política econômica. À época, a posição do Partido dos Trabalhadores a respeito do Plano Real inspirava alguma ambigüidade que acabou ceifando as chances eleitorais de Lula em 94 e 1998.

Considerando seu sucesso na luta contra a inflação, como avaliar a política econômica adotada por FHC em seus oito anos de mandato presidencial? Evidentemente, a centro de sua estratégia de política econômica concentrou-se na busca incessante e desesperada pela estabilidade inflacionária. O objetivo em si é de fato gerador de ganhos sociais e econômicos significativos e nesse sentido, compreende-se que toda energia de seu governo tenha se voltado para o combate 
e estabilização da inflação. Como a tabela ao final mostra, a inflação baixa acompanhou toda a experiência do governo tucano. No primeiro mandato presidencial (1995-1998), a inflação acumulada foi de 38, 85\%, e no segundo mandato (1998-2002), a inflação acumulada foi de $35,11 \%$, somando ao final de dois mandatos, inflação de 73,96\%.

Embora se deva reconhecer que o governo FHC realmente apresentou uma agenda de reformas que não se esgotavam somente no combate à inflação, e nesse caso, me refiro às políticas orientadas para o mercado, as reformas liberais que FHC implementou como, as privatizações de empresas estatais de amplos setores da infra-estrutura, a abertura comercial, maior atração ao capital estrangeiro etc. Os impactos das políticas liberais para a economia brasileira são importantes, referências podem ser encontradas nas análises de (FIORI, 2001) e (GONÇALVES, 2002). O governo FHC adotou uma agenda ampla de reformas estruturais, que transitou da esfera econômica à esfera política, envolvendo a economia e o Estado brasileiro, segundo uma orientação reformista de caráter liberal.

Por essa via de análise, as políticas de reforma orientada para o mercado impostas por FHC atingiram algum sucesso importante em termos de esvaziamento das funções econômicas do Estado brasileiro de origem nacional-desenvolvimentista, e de uma maior internacionalização da estrutura produtiva do país segundo uma lógica de inserção da economia e da sociedade brasileiras na dinâmica da globalização e da ideologia neoliberal. Mas é necessário, no entanto, questionar os custos e limites dessas políticas de abertura do ponto de vista da desnacionalização produtiva e dos seus impactos no capitalismo nacional. De outra parte, a própria centralidade da política econômica, voltada quase que exclusivamente para o combate à inflação também deve ser objeto de análise crítica do governo FHC. Como já afirmaram Freire e Nobre (1998), a era FHC pode ser caracterizada como uma era de "estabilidade imperfeita". Nesse aspecto, é importante considerar os altos custos financeiros, econômicos e sociais da política econômica de controle da inflação.

Um critério de análise da política econômica se refere ao desempenho da economia sob o comando de FHC. No quesito cresci- 
mento econômico, a avaliação do governo FHC foi de grande irregularidade, onde a economia vivenciou um comportamento típico de vôo de galinha, com média de crescimento de 2,0\% ao ano nos oito anos de Fernando Henrique Cardoso no poder, acumulando crescimento de $10,3 \%$ no primeiro mandato e $8,4 \%$ no segundo. Sob José Sarney, a economia brasileira cresceu a uma média 4,0\% ao ano, acumulando $22,09 \%$ de avanço no PIB. No final, a média de crescimento de FHC é naturalmente menor do que o registrado pelos militares e durante os governos democráticos, entre Sarney e Lula, FHC ganha apenas do período Collor, quando a economia experimentou recessão de -3,86\% nos dois anos do ex-governador de Alagoas no poder.

Como se pode constatar, o governo FHC conseguiu atingir taxas de crescimento do PIB numa média de $2,4 \%$ no primeiro mandato (1994-1998) e 2,1\% no segundo mandato (1999-2001) resultado bastante inferior aos registrados nos governos militares pós-64 e mesmo durante o governo de transição democrática de José Sarney (1985-1990). Segundo levantamento do economista Reinaldo Gonçalves (2003), o crescimento do produto no período pós-1930 foi em média de 5,0\% ao ano no Brasil, resultado superior ao de muitos países capitalistas avançados. Olhando para os dados dos anos FHC, observa-se grande irregularidade no desempenho da economia brasileira, num padrão do tipo stop and go com crescimento de 4,2\% em 1994, primeiro ano do Real, atingindo 0\% em 1998. Neste ano, as crises financeiras deflagradas na Rússia e Ásia impactaram diretamente sobre a economia brasileira. Desse modo, longe de uma política econômica que levasse o país para a estabilidade definitiva e crescimento econômico sustentável e duradouro, o binômio estabilidade/instabilidade parecerem ter marcado profundamente o período FHC no poder entre os anos 94-2001.

Em função das contradições encontradas na política econômica de FHC, cabe a pergunta: qual a lugar da inflação no projeto político de FHC? Em que medida a política de combate a inflação tinha objetivos mais amplos que a mera estabilização dos preços e converteu-se numa política estratégica e estruturante para seu projeto de reorganização do capitalismo brasileiro em novas bases, se- 
gundo a dinâmica da globalização e do neoliberalismo? De fato, é possível afirmar que a política de combate à inflação e o sucesso do Plano Real passou a ser encarado como uma política condicional, isto é, uma etapa necessária para a execução de outras políticas de reforma. O sucesso do Real tornou-se condição necessária para o sucesso na implantação das outras políticas da agenda reformista do governo FHC. Do ponto de vista macro político, o controle da inflação também representou a reorganização do poder do Estado sobre a sociedade, um novo pacto social entre Estado e sociedade e de afirmação do poder político estatal.

Em quase duas décadas de crise econômica e inflacionária, a capacidade de intervenção do Estado sobre a sociedade e a economia ficaram seriamente enfraquecidas. Nesse sentido, ao menos no plano simbólico, a vitória de FHC na luta contra a inflação representou um ato de reafirmação do poder político estatal e do próprio poder Executivo sobre a sociedade e a economia. Como se sabe, o processo de redemocratização política do país foi marcado pela maior e mais grave crise econômica da história, enfraquecendo a intervenção do Estado sobre a sociedade, criando vazios de legitimidade do poder político, comprometendo seriamente a capacidade do Estado governar a sociedade, tornando frágil as bases de compromisso com o regime democrático. Sobre essa questão, consultar Reis \& O’Donnell (1988).

Nesse aspecto das relações entre economia e política, a luta contra a inflação se converteu numa luta também pela construção do regime democrático no Brasil, na medida em que o regime inflacionário inercial brasileiro poderia colocar em xeque o processo de transição democrática num mínimo de segurança social e estabilidade econômica. Os governos da primeira geração da transição democrática (1985-1994) conviveram intensamente com essa situação de instabilidade e insegurança. Desse modo, a luta contra a inflação alta no Brasil representou uma luta política de afirmação do regime democrático. A vitória política de FHC em controlar a inflação inercial no Brasil significou também uma vitória para a democracia, e uma contribuição importante para o fortalecimento do consenso democrático no Brasil. 
Outra dimensão relevante da vitória política de FHC na luta contra a inflação a partir do Plano Real, diz respeito à possibilidade de uma sociedade civilizada no Brasil. Como se sabe, processos agudos de inflação promovem a erosão das bases tradicionais de sociabilidade. Os princípios de confiança e de relações de reciprocidade são fragilizados diante de experiências prolongadas de inflação alta. A situação histórica vivenciada pela Alemanha e Hungria dos anos 20 do século XX foram exemplos dramáticos de violência social e de radicalização política. No caso alemão, a crise social e econômica do pós Primeira Guerra Mundial (1914-1919) facilitou o espectro da radicalização política que levou o país ao nazismo e a deflagração de uma nova guerra mundial de proporções assustadoras para toda a humanidade. Os impactos da inflação na vida social são bem demonstrados em Viera, Barbosa, Prado, Leopoldi e D’Araújo (1993).

No Brasil dos anos 80 e 90 a guerra de todos contra todos adquiriu outro sentido: a sobrevivência básica e cotidiana de uma luta diária contra uma economia de preços sempre em alta, e as dificuldades para conseguir acompanhar a velocidade dos aumentos de preços. Os salários e a renda dos assalariados tornavam-se alvos preferenciais do ritmo dos aumentos. O conflito distributivo instaurado pela inflação alta leva uma situação social voltada pela lógica da sobrevivência, e da busca por alguma proteção contra a ferocidade da inflação alta. A sociedade torna-se uma sociedade do salve-se quem puder num regime de inflação alta como se viveu no Brasil. Na experiência brasileira de inflação, as regras da civilização são fragilizadas e a inflação se converte em principal fator de erosão das bases sociais.

Torna-se essencial considerar a dimensão política, econômica e social das políticas de estabilização de preços em vigor a partir de 1994 com o Plano Real e seus impactos na sociedade, na economia e na política. Por vezes, as abordagens econômicas se concentram apenas nos benefícios econômicos gerados pela estabilização, sem levar em conta os impactos positivos na vida social e política de uma economia sem inflação. Considera-se que a luta contra a inflação assumiu um papel civilizatório na recente trajetória do país pela redemocratização política. De fato, a luta contra a inflação, foi benéfica 
à construção da democracia no Brasil. A inflação possui um forte caráter conflitivo que inviabiliza a governabilidade política num mínimo de estabilidade e segurança institucional.

A política econômica de FHC sofreu mudanças entre o primeiro e segundo mandato. No primeiro mandato presidencial, a política cambial foi mantida em regime de câmbio fixo, ancorando o Real no Dólar como forma de segurar o valor da moeda e assegurar patamares de preços condizentes com os objetivos do Plano. A partir do segundo mandato presidencial, em 1998, a política de câmbio fixo foi alterada para o regime de câmbio flutuante. Na ocasião, o próprio governo não esclareceu os motivos da mudança da política cambial, que fora feita logo após os resultados das urnas confirmarem a vitória eleitoral ao grupo político de FHC. De todo modo, a manutenção da política de câmbio fixo em regime de paridade com o dólar, obteve grande aceitação popular, pela ilusão de possuir uma moeda forte e de maior acesso ao consumo. De outro lado, a valorização do caráter simbólico da moeda forte no imaginário social, apesar de positiva em contextos de alta inflação, não deixou de trazer grande custo financeiro ao país, promovendo aumento no endividamento e incertezas geradas pelo movimento dinâmico das moedas centrais no contexto da competição entre os países de capitalismo avançado.

De todo modo, FHC conseguiu duas vitórias eleitorais consecutivas contra Lula do PT por força de sua estratégia em vencer a inflação e produzir no país o chamado choque de capitalismo e modernização. Pode-se afirmar que em grande parte de seus objetivos estratégicos foi alcançado, como a manutenção de taxas de inflação baixas e controladas ao longo dos seus dois oito anos de governo, o esvaziamento do papel do Estado da economia através das privatizações de empresas estatais, e as reformas do campo legal que quebraram o monopólio estatal da Petrobrás e outras medidas de reforma do arcabouço legal do país segundo a orientação ideológica neoliberal.

Entretanto, a partir do segundo mandato presidencial (19982002), o governo FHC passou a receber uma intensa crítica sobre a necessidade de se adotar uma política de desenvolvimento. Sendo clara a sua política de estabilização, quando se refere às políticas de 
desenvolvimento, não havia essa clareza. Essa percepção era sentida dentro e fora do governo. E mesmo no que se refere à política econômica, nunca houve unanimidade no interior do governo. Sallum Jr (1998) demonstrou a existência de uma clivagem entre os economistas do governo FHC produzida basicamente em torno do dilema estabilização versus crescimento. Os liberais-fundamentalistas, agrupados no Ministério da Fazenda e Banco Central, eram favoráveis ao aprofundamento da política de abertura econômica e na aposta na capacidade do mercado atrair maior investimento privado para o país, enquanto os liberais-desenvolvimentistas, localizados no BNDES e Ministério do Planejamento, defendiam a adoção de políticas de crescimento e seletividade na abertura econômica para exterior em função dos seus impactos na indústria nacional.

Apesar das críticas, FHC conseguiu manter a inflação baixa, estabelecendo a política do chamado tripé macroeconômico: o regime de metas de inflação que deve se situar entre 4,5\% a 6,5\% ao ano, o câmbio flutuante, e a política de superávit primário, isto é, a economia de gastos ao redor de 3,5\% do PIB. De modo geral, essa política promoveu efeitos positivos em termos de responsabilidade fiscal e de uma maior adequação do Estado brasileiro a nova era de racionalidade do gasto público e de superação do populismo fiscal. Por outro lado, para muitos críticos, essa política do governo FHC em relação aos mercados e ao capital financeiro, acabou prejudicando a adoção de políticas de crescimento e planejamento econômico e no sentido de dotar o Estado de capacidade para investir. A crise energética de 2000 pode ser lida como um sinal evidente do esvaziamento do Estado promovida pelo governo FHC, e sua adesão pouco crítica ao conteúdo conservador e passivo das medidas do tripé macroeconômico.

A partir do segundo mandato, FHC procurou responder às críticas de que seu governo não detinha um projeto político de crescimento e que se voltava até então, apenas para a estabilização econômica. O abandono do ideário desenvolvimentista era evidente naquela altura dos anos de 1999 e 2000. A criação do Ministério do Desenvolvimento em 2001 representou um movimento reativo do governo FHC em direção a uma perspectiva política pró-ativa 
na participação do Estado no desenvolvimento. Como os dados indicam, os resultados econômicos do segundo mandato presidencial foram ainda piores quando comparado com o primeiro mandato presidencial, com crescimento acumulado de 8,4\% entre os anos 19982002 , contra 10,3 do primeiro mandado. A sensação de um governo sem clareza de projeto no segundo período de FHC como presidente, aliado ao contexto produzido pela crise energética, com necessidade do governo adotar o racionamento de energia, colocou em xeque o viés neoliberal do seu governo, ao atestar que a falta de planejamento estatal das políticas governamentais na área poderia levar o país a beira de uma crise enérgica de grandes proporções econômicas.

\section{O GOVERNO LULA}

A eleição de Luiz Ignácio Lula da Silva para a Presidência da República em 2002 foi cercada de enormes expectativas quanto ao seu mandato. Depois de três tentativas frustradas desde a histórica eleição de 1989, passando pelos pleitos de 1994 e 98, Lula e o PT finalmente chegavam ao poder político máximo do país. De fato, a chegada de Lula e o PT ao poder político principal do Estado brasileiro foi um acontecimento marcante na história moderna do país, tendo como referência a biografia do ex-presidente, rica em significado político e simbólico. Na verdade, a vida de Lula é uma ilustração viva do épico social impulsionado pela modernização capitalista que o Brasil experimentou entre os anos 50 e 70 . O próprio PT, nascido em 1982 a partir das lutas operárias de 1978, 79 e 80 chega ao poder como novidade inédita enquanto partido de esquerda no Brasil.

Ao chegar ao poder em 2002, Lula e o PT já haviam adquirido um considerável estoque de capital político, com o acúmulo da experiência das eleições nacionais anteriores, bem como na ocupação do poder em escala local em cidades relevantes do Sul/Sudeste do país. No caso das eleições derrotadas por Lula em 89, 94 e 98 o tema da inflação pode ser entendido como uma razão importante para explicar algumas dessas derrotas eleitorais. Em 1989, adotando uma perspectiva política centrada na classe operária sindicalizada, o 
partido não possuía uma clara plataforma econômica contra a inflação ou um esboço de política econômica que contemplasse o debate em torno da inflação, bem como uma política de alianças com outros setores da sociedade.

Nas eleições de 1994, o problema da inflação e o enfrentamento político do Plano Real encabeçado por FHC colocou a candidatura petista numa posição defensiva. A escolha do economista Aloísio Mercadante para vice-presidente de Lula na chapa de 94 foi uma tentativa de responder ao problema econômico e inflacionário. Naquele contexto, Lula e o PT não haviam sido capazes de formular um discurso político alternativo ao Plano Real e sua candidatura ficou ausente de um programa de combate a inflação eficiente para apresentar ao mercado político naquele momento crítico.

Aquele contexto instável das eleições presidenciais de 1994 também pode ser pensado como um momento de transição política, de final do governo provisório de Itamar Franco e de transição econômica, de recontratualização da economia em direção a nova moeda, o Real. A derrota de Lula pode ser creditada à ineficiência com que o partido de Lula lidou com a questão do combate a inflação naquele contexto. Em 1998, a persistência da inflação na agenda eleitoral e o medo de Lula mudar o Plano Real levaram mais uma vez a vitória eleitoral de FHC e seus aliados políticos. O espectro do medo de volta da inflação produziu efeitos importantes nas duas eleições, 94 e 98 . Em 1998, FHC inclusive jogou politicamente com esse sentimento de medo de volta da inflação, ao esconder a mudança da política cambial, que foi alterada para o regime de câmbio flutuante logo após a divulgação dos resultados oficiais confirmando sua vitória.

Nas eleições presidências de 2002, o cenário político e econômico era bastante distinto de 89, 94 e 98 quando o PT e Lula pareceram estar perdidos em oferecer uma proposta eficaz de política de combate a inflação. O governo FHC por seu lado, também dava sinais de esgotamento frente às críticas dirigidas ao governo no segundo mandato presidencial (1998-2002). A imagem principal que ficou na memória coletiva foi de um governo sem agenda no segundo mandato, situação bastante diferente do que foi o primeiro mandato 
quando FHC tinha de fato uma agenda de reformas para o país e perseguiu seus objetivos com o objetivo de impor o seu projeto.

Ao lado do esvaziamento do projeto político de reformas liberais do governo FHC, os anos 2000 também experimentaram mudanças políticas relevantes no contexto latino-americano. Em muitos países da região, as críticas ao neoliberalismo e seu pacote de políticas acabaram levando ao poder grupos políticos de esquerda baseados em forte rejeição ao modelo neoliberal de sociedade, de economia e de política. Em muitas situações nacionais, havia um esgotamento de um conjunto de políticas adotadas nos anos 90, e a compreensão geral de que ao final de um pouco mais de uma década de reformas, poucos resultados em termos de maior crescimento econômico foram realmente alcançados. Em muitos países da região sul-americana, as críticas ao modelo do Consenso de Washington eram generalizadas.

No caso brasileiro, esse contexto regional de questionamento ao neoliberalismo beneficiou a vitória da candidatura de Lula. Naquelas eleições de 2002 estavam em jogo dois projetos distintos de sociedade, e José Serra do PSDB não conseguiu defender o legado neoliberal de FHC com competência e clareza na disputa contra Lula. No entanto, é importante enfatizar que mesmo sob condições objetivas de vitória eleitoral, ainda pairavam incertezas em relação à viabilidade econômica do projeto petista de poder. Assim como em 1989 e nas demais eleições disputadas por Lula, o empresariado manifestava um sentimento de dúvidas sobre a política econômica a ser adotada pelo PT, a postura em relação aos compromissos fiscais de FHC, e, sobretudo, sobre a continuidade do Plano Real. A inflação apresentava sinais de descontrole durante as eleições de 2002, numa clara demonstração da desconfiança dos agentes econômicos em relação à candidatura de Lula a Presidência da República. Durante o curso do processo eleitoral, o grupo petista lançou a chamada Carta ao Povo Brasileiro, um documento onde o partido reafirmava seu compromisso com o cumprimento dos contratos celebrados e o não rompimento com os fundamentos econômicos assumidos pela gestão FHC.

Com a vitória política de Lula e do PT consagrada na legitimidade das urnas, muitos à esquerda política supunham uma virada 
radical na política econômica. A enorme expectativa popular em torno da chegada de um autêntico líder operário e popular ao posto máximo do poder político no país foi cercada de expectativas quanto a mudanças nos rumos da economia e da sociedade brasileira. Para setores do partido de Lula, essas mudanças poderiam conduzir o país ao socialismo ou num tipo de capitalismo democrático, segundo um modelo social-democrático clássico. A agenda econômica do governo, para muitos, não poderia descuidar de políticas que promovam a retomada do crescimento econômico e a adoção de políticas distributivas que atendessem ao imperativo político de igualdade social e equidade, segundo um projeto democrático de sociedade.

Muitas dessas expectativas sociais e políticas foram frustradas nos primeiros anos do mandato de Lula em razão da inflação. A retomada da inflação nos anos 2003 e 2004 obrigaram o governo Lula a adotar uma política econômica conservadora e ortodoxa, com a utilização dos instrumentos tradicionais, como juros altos e a queda drástica na atividade econômica como forma de combater a inflação. O Ministro da Fazenda indicado por Lula para comandar a política econômica, Luiz Antonio Palocci, médico e ex-prefeito de Ribeirão Preto-SP, acabou por adotar uma política econômica afinada com as linhas adotadas pelo seu antecessor, Pedro Malan.

As conseqüências políticas com a adoção da mesma política econômica de FHC foram grandes. O baixo desempenho da economia no início do mandato de Lula, que chegou a registrar crescimento $0 \%$ em 2003, sugeria uma grande decepção, afinal, qual a diferença entre Lula e FHC no campo da política econômica? Embora a posição de Lula fosse crítica em relação a política econômica e da necessidade política de justificar uma diferença entre os dois governos (Palocci, 2003) o fato concreto é que seu governo foi levado a adotar medidas impopulares para controlar a inflação. Nesse sentido, seria a ameaça da volta da inflação o principal fio condutor da decepção do governo Lula? Leda Paulani (2006) fala em verdadeiro estado de emergência inflacionário para explicar a fácil adesão de Lula ao esquema hegemônico dominante de política econômica nos anos sob a condução de Palocci. 
Os primeiros anos do governo Lula, bem como as suas declarações posteriores, indicam que a experiência trágica da inflação nos anos 80 e 90 sedimentaram a formação de um consenso político entre os dois principais partidos políticos sobre a necessidade do controle da inflação. Esse consenso mostra que o controle da inflação é prioridade para qualquer política econômica responsável. O que sugere também é que políticas de controle da inflação devem adotadas independentes dos custos sociais e econômicos. É possível pensar num pacto celebrado entre PT e PSDB num tipo consenso anti-inflacionário, celebrado no mesmo tipo de política econômica a ser adotada. A própria dinâmica da transição entre os governos FHC e Lula, um padrão altamente civilizado e respeitoso, inédito para o padrão histórico brasileiro, dá uma idéia da aproximação entre os dois partidos. A manutenção do Plano Real selou efetivamente um nível de compromisso político entre os partidos PSDB e PT na condução do país, superado positivamente o radicalismo de medidas, indicando maior proximidade entre os dois partidos em matéria de política econômica.

A experiência dos governos FHC e Lula, governos de segunda geração de transição democrática, sugerem um contexto político e econômico distinto dos governos da primeira geração, dos anos 80 e 90. Nos anos FHC e Lula, sem dúvida se referem um período com maior estabilidade política e econômica, e os anos 1994-2010 foram de estabilidade política e inflação sob controle. Embora os custos sociais e econômicos da política de estabilização econômica não devem ser novamente desconsiderados, não se deve minimizar o significado da estabilidade econômica e política para um país que iniciou a transição democrática com enormes percalços políticos e econômicos. Nesse aspecto, a contribuição de FHC e Lula para o fortalecimento do processo de construção democrática no Brasil recente não pode ser desprezado. A dimensão econômica desse processo tem a ver é claro, com a situação econômica do país a partir de 1994 e a estabilidade da inflação. Sem o controle definitivo da inflação, a nova democracia brasileira iria sofrer com essa doença do inflacionismo permanente, doença geradora de conflitos e incertezas na sociedade e na economia. 
A gestão Antonio Palocci no Ministério da Fazenda, marcada pela orientação ortodoxa na política econômica perdurou por três anos, entre 2003 a 2005. Sua queda foi precipitada pela crise política causada pela quebra do sigilo bancário de um caseiro, que provocou enorme mal estar no governo Lula, abrindo caminho para nomeação do professor da PUC-SP, de linhagem desenvolvimentista, Guido Mantega. Inegável dizer que Palocci foi o principal responsável pela política de controle da inflação nos anos 2003-2005, quando havia sinais claros de descontrole e incerteza dos mercados em relação à gestão petista na economia. $\mathrm{O}$ ex-ministro Palocci também foi um dos principais responsáveis pela articulação do grupo petista com o empresariado nacional e um dos redatores da Carta ao Povo Brasileiro, lançado durante a campanha eleitoral com o objetivo de tranqüilizar os mercados e o empresariado. Além disso, o papel de Palocci na liderança da equipe de transição entre FHC e Lula foi igualmente relevante.

A chegada de Guido Mantega no Ministério da Fazenda foi uma importante mudança na orientação da política econômica no governo Lula. Economista e Cientista Social com formação na USP, com tese de doutorado defendida no Departamento de Sociologia da mesma universidade, defendida em 1983, tendo inclusive Fernando Henrique Cardoso e Luiz Carlos Bresser-Pereira em sua banca de argüição de tese. Mantega era um economista ligado ao PT de longa data, porém de perfil político modesto e mais ligado aos bastidores da política e de aconselhamento econômico do presidente Lula. Diferente de Palocci que atuou diretamente na arena política, ocupando cargo de prefeito em importante cidade do interior paulista, e mandato de deputado federal pelo Estado de São Paulo, ambos pelo PT.

A nomeação de Guido Mantega ao Ministério da Fazenda representou a mais importante mudança de rumos na condução da política econômica sob o governo Lula entre a orientação ortodoxa e a orientação desenvolvimentista. Importante enfatizar que mesmo sob uma nova diretriz ideológica, a política econômica de Lula com Mantega não deixou de vincular-se aos fundamentos da política econômica do governo anterior, e principalmente com a inflação. Nesse sentido, a adoção de uma estratégia de caráter expansionista 
deveria ocorrer levando em conta a política de controle da inflação e portanto, um tipo de ação calculada sem colocar em risco as metas de inflação estabelecidas no governo FHC. Pode-se afirmar que entre termos políticos e econômicos, o governo Lula estava numa importante tensão. De um lado, a necessidade de manter a política de controle de inflação, que desde FHC deve estar sob o regime de metas de inflação, devendo obrigatoriamente oscilar entre 4,5\% a $6,5 \%$ ao ano, sem comprometer os ganhos da estabilização depois de uma longa e descontrolada inflação. De outro, a questão política fundamental para Lula: promover crescimento econômico acima do obtido por FHC como forma de justificar sua posição política como líder de uma nova coalizão política e social.

Nos primeiros anos de seu primeiro mandato presidencial, não estava claro para Lula que sua posição a frente do governo seria bem sucedida, ou seja, se a política de controle de inflação seria preponderante sobre a política de crescimento econômico e qual sentido, Lula iria optar. A partir de 2005 e principalmente a partir do segundo mandato, em 2006, que a política econômica do governo petista teria uma clareza em seus objetivos de crescimento e desenvolvimento. E nesse caso, mais do que a política econômica em si, foram às outras políticas adotadas por Lula que se revelaram bem sucedidas em criar um ambiente favorável ao crescimento da economia. A política de transferência direta de renda, criada em 2003, e a política de valorização do salário mínimo, com reajustes acima da inflação, ajudaram decisivamente a impulsionar o acesso ao consumo e ampliação do mercado interno de consumo, grande aposta do governo para alavancar a economia brasileira.

A equação positiva para o governo Lula foi a relação positiva entre a política social e a política econômica que acabou criando as condições ideais para uma maior expansão da economia, que se verificou no segundo mandato presidencial, a partir de 2006. A expansão do crédito popular para consumo de bens, imóveis e automóveis, numa verdadeira política de incentivo ao consumo tornou a economia do país menos vulnerável às oscilações do mercado internacional e proporcionou a inclusão de milhões no mercado con- 
sumidor. Embora o governo Lula e a política econômica conduzida por Mantega à frente do Ministério da Fazenda tenham continuado o chamado tripé macroeconômico básico da estabilização, o que para muitos, representou a "macroeconomia da estagnação" (Bresser-Pereira, 2007), Lula conseguiu uma flexibilização na política econômica que se revelou exitosa.

A escolha pelo mercado interno, claramente inspirado no modelo de capitalismo inclusivo das economias desenvolvidas, foi o grande trunfo social, político e econômico do governo Lula, na medida em que possibilitou ao governo sedimentar uma aliança com os setores populares, que antes, rejeitavam a figura de Lula e do PT. (Singer, 2012). Nesse sentido, essa escolha política em privilegiar setores excluídos do consumo de massa fortaleceu o consenso em outros grupos sociais em torno da política econômica na medida em que os objetivos de alcançar maior crescimento com taxas de inflação sob controle ampliaram o leque de alianças e apoio que o governo Lula poderia obter. No caso do empresariado industrial de face nacional, a utilização exponencial do BNDES como banco público de apoio a iniciativas ao capital privado nacional incluiu também a classe economicamente dominante no interior do bloco de poder petista.

A experiência dos anos 2003-2010 no que diz respeito à reorganização empresarial tem sido de grande monta no Brasil contemporâneo. A aliança obtida por Lula entre a classe trabalhadora de um lado e o empresariado nacional do outro, alicerçada numa política econômica que logrou obter crescimento com baixa inflação, sugere uma experiência bem sucedida para o governo Lula. Em termos de estabilidade política e estabilidade econômica, aliada a um forte viés distributivo, conferem ao período Lula uma era quase inédita quando se olha a história moderna do país. Como se sabe, a trajetória brasileira de modernização social e econômica não foi devidamente acompanhada de políticas sociais e de direitos de cidadania. O caráter do desenvolvimentismo do período anterior reforçou o caráter econômico do Estado, mas não o seu caráter social. E o governo Lula procurou deliberadamente reforçar o caráter social do Estado brasileiro através principalmente do programa Bolsa Família e outras iniciativas. 
O governo Lula conseguiu construir uma aliança política com a classe trabalhadora e a classe capitalista nacional em torno de um pacto pelo desenvolvimento econômico e distribuição de benefícios sociais. Na verdade, esse pacto pode ser pensado como um aspecto mais amplo de atores políticos, incluindo movimentos sociais, estudantes, o agronegócio etc, como um tipo de aliança neo-desenvolvimentista segundo Boito Jr. ou um pacto neo-desenvolvimentista para Bresser-Pereira. O controle da inflação e a situação de estabilidade, aliada a política de retomada do crescimento econômico, ajudaram Lula no seu projeto político de reorganização do capitalismo brasileiro em outras bases sociais e políticas.

No conhecido binômio inflação versus crescimento econômico, o governo Lula não se saiu mal, quando se compara com outros governos da transição democrática. Do ponto de vista da inflação acumulada, o governo Lula cravou $25,73 \%$ no primeiro mandato (2003-2006), e 20,58\% no segundo (2007-2010), índice inferior a todos os governos da transição democrática. Em relação ao crescimento econômico e expansão do PIB, o governo Lula acumulou crescimento de $12,9 \%$ do PIB no primeiro mandato e $17,9 \%$ no segundo, acumulando crescimento total de $30,8 \%$, contra $18,4 \%$ dos governos FHC, como se pode constatar em quadro abaixo.

Inflação acumulada dos governos democráticos (1985-2010):

\begin{tabular}{|l|l|l|}
\hline GOVERNO & PERÍODO & INFLAÇÃO \\
\hline Sarney & $1985-1989$ & $3.638,43 \%$ \\
\hline Collor & $1990-1992$ & $3.212,74 \%$ \\
\hline Itamar & $1992-1994$ & $3.393,58 \%$ \\
\hline FHC I & $1995-1998$ & $38,85 \%$ \\
\hline FHC II & $1998-2002$ & $35,11 \%$ \\
\hline Lula I & $2003-2006$ & $25,73 \%$ \\
\hline Lula II & $2007-2010$ & $20,58 \%$ \\
\hline
\end{tabular}

Fonte: o autor

Desempenho econômico dos governos democráticos (1985-2010):

\begin{tabular}{|c|c|c|}
\hline GOVERNO & PERÍODO & $\begin{array}{c}\text { CRESCIMENTO DO PRODUTO } \\
\text { INTERNO BRUTO - PIB }\end{array}$ \\
\hline Sarney & $1985-1990$ & $22,09 \%$ \\
\hline Collor & $1990-1992$ & $-3,86 \%$ \\
\hline Itamar & $1992-1994$ & $10,97 \%$ \\
\hline
\end{tabular}

207| Século XXI, Revista de Ciências Sociais, v.3, nº 2, p.182-212, jul./dez. 2013 ISSN: 2236-6725 


\begin{tabular}{|c|c|c|}
\hline GOVERNO & PERÍODO & $\begin{array}{c}\text { CRESCIMENTO DO PRODUTO } \\
\text { INTERNO BRUTO - PIB }\end{array}$ \\
\hline FHC I & $1995-1998$ & $10,3 \%$ \\
\hline FHC II & $1998-2002$ & $8,4 \%$ \\
\hline Lula I & $2003-2006$ & $12,9 \%$ \\
\hline Lula II & $2007-2010$ & $17,9 \%$ \\
\hline
\end{tabular}

Fonte: o autor

\section{CONCLUSÕES}

A experiência dos governos FHC e Lula oferecem um importante campo de análise política sobre os percalços econômicos do processo de redemocratização política do Brasil contemporâneo. A luta contra a inflação vivenciada pelos grupos políticos desde 1986 com o Plano Cruzado, proporcionou um enorme aprendizado em termos práticos e teóricos sobre como lidar com um problema grave como a inflação, e ao mesmo tempo, ajudou a sedimentar medidas para evitar a volta da escalada inflacionária entre nós. No entanto, é importante reconhecer o caráter dramático da experiência dos anos 80 e 90 enquanto experiência aguda de crise social, política e econômica causada pela inflação alta e descontrolada. E nesse aspecto, é quase comum afirmar que a questão da inflação tornou-se uma espécie de fantasma que ronda a tomada de decisão de política econômica no país. E ao que aparece, continua rondando o espectro da política brasileira contemporânea como um fantasma.

De fato, a experiência acumulada dos governos FHC e Lula, de origem partidária e de trajetórias políticas e pessoais tão distintas como são PSDB e PT, mostra que no campo da política econômica, as convergências são muito maiores do que as divergências. Se o governo FHC priorizou estabilidade econômica e o governo Lula reforçou o caráter social do Estado brasileiro, no caso da política econômica, o compromisso de ambos os governos foi com a manutenção da inflação baixa e controlada, segundo o regime de metas adotado. Essa superação do radicalismo político dos grupos relevantes da disputa política nacional ajudou a fortalecer a democracia no Brasil, na medida em que a superação do drama inflacionário contribuiu decisivamente para a melhora das condições sociais e econômicas da nova democracia brasileira. 208| Século XXI, Revista de Ciências Sociais, v.3, nº 2, p.182-212, jul./dez. 2013 ISSN: 2236-6725 
A luta bem sucedida contra a inflação a partir de 1994 e a experiência dos governos FHC e Lula mostram um maior amadurecimento da democracia brasileira. A persistência da inflação alta poderia jogar contra o processo de afirmação do regime democrático num país de tradição autoritária como o Brasil. Nesse sentido, os governos FHC e Lula contribuíram de modo fundamental para um ambiente de civilidade política, estabilidade econômica e principalmente, de justiça social. De uma maneira consistente, é possível afirmar, concordando com o economista Bresser-Pereira que estamos vivendo no Brasil um novo momento: uma era de democracia política, combinada com economia em crescimento e justiça social. Esses três elementos juntos consagram o período dos anos 2000 como um período de ganhos sociais e econômicos indiscutíveis. No entanto, não é possível afirmar que o problema da inflação esteja completamente superado no Brasil. É correto pensar num verdadeiro estado mental de medo que paira sobre nossas consciências como um sentimento de medo e pânico sobre o provável retorno da inflação alta.

Esse sentimento difuso de retorno de uma nova escalada inflacionária nos ensina muito sobre a situação da inflação no Brasil pós-estabilidade. Afinal, há que se questionar sobre o caráter da estabilidade conseguida, e se de fato vivemos sob uma estabilidade permanente e sustentável ou se trata de uma estabilidade passageira e sujeita a retrocessos e imprevistos. No mais, é sempre importante considerar nas condições econômicas do Brasil contemporâneo, que é realmente relativo falar em estabilidade como um projeto sustentável e de longo prazo, diante dos inúmeros fatores de instabilidade presentes na economia brasileira e na economia internacional. O risco é um elemento presente na vida econômica das nações, e o caso do Brasil não é diferente. Nesse sentido, a inflação brasileira, mesmo sob o controle proporcionado pela política econômica de FHC e Lula, não está totalmente sob controle, como nos países de capitalismo avançado. Políticas amargas e impopulares sempre estarão à disposição para os governos democráticos a qualquer sinal de descontrole dos preços. Portanto, a economia e sociedade brasileira não estão definitivamente livres da inflação. 
Nesse aspecto da questão, a nova democracia brasileira, que nasceu sob os percalços da maior da crise econômica da história moderna do país, ainda não conseguiu superar seus principais problemas econômicos, e a inflação, mesmo sob controle, é um mal prestes a explodir a qualquer momento, necessitando de cuidados e vigilância permanentes. De todas as patologias do Brasil, a fundamental doença da democracia brasileira contemporânea é o inflacionismo, que ainda vai exigir cuidados especiais do Estado e da política de coordenação macroeconômica, obrigando ao sacrifício de outras prioridades políticas e do sacrifício da própria sociedade brasileira.

\section{REFERÊNCIAS}

ABRANCHES, Sérgio Henrique Hudson. A Sociologia Política da Inflação. In: VIEIRA, José Ribas, BARBOSA, Livia Neves de Holanda, PRADO, Luis Carlos Delorme, LEOPOLDI, Maria Antonieta e D’ARAÚJO, Maria Celina. Na Corda Bamba: doze estudos sobre Cultura da Inflação. Rio de Janeiro: Relume-Dumará, 1993.

ANDERSON, Perry. O Brasil de Lula. Novos Estudos CEBRAP, nº 91, p.23$52,2011$.

ARIDA, Pérsio (Org.). Brasil, Argentina e Israel: inflação zero. São Paulo: Paz e Terra, 1986.

BELIEIRO JR, José Carlos M. Política Econômica e Democracia: qual política econômica para a democracia brasileira? In: Boletim, Revista da Área de Humanas. CLCH/UEL, nº 48, 2005.

BRESSER-PEREIRA, Luiz Carlos. Macroeconomia da Estagnação: crítica da ortodoxia convencional no Brasil pós-1994. São Paulo: Editora 34, 2007.

. Desenvolvimento e Crise no Brasil: história, economia e política de Getúlio Vargas a Lula. São Paulo: Editora 34, 2004.

. Os Tempos Heróicos de Collor e Zélia: aventuras da modernidade e desventuras da ortodoxia. São Paulo: Nobel, 1991.

BIELSCHOWSKY, Ricardo (Org.) Políticas Para a Retomada do Crescimento: reflexões de economistas brasileiros. Rio de Janeiro: IPEA, 2002. 
BORSANI, Hugo. Eleições e Economia: instituições políticas e resultados macroeconômicos na America Latina (1979-1998). Belo Horizonte/ Rio de Janeiro: Editora da UFMG/IUPERJ, 2003.

FIORI, José Luís. 60 Lições dos 90. Rio de Janeiro: Record, 2001.

GONÇALVES, Reinaldo. Vagão Descarrilhado: o Brasil e a economia global. Rio de Janeiro: Record, 2002. - A Herança e a Ruptura: cem anos de política econômica e propostas para mudar o Brasil. Rio de Janeiro: Garamond, 2003.

LEITÃO, Mirian. A Saga Brasileira: a longa luta de um povo por sua moeda. Rio de Janeiro: Record, 2011.

NOBRE, Marcus e FREIRE, Vinicius Torres. Política Difícil, Estabilização Imperfeita: os anos FHC. Novos Estudos CEBRAP, n 51, p.123-147, 1998.

PALOCCI, Antônio. Sobre Formigas e Cigarras. Rio de Janeiro: Objetiva, 2007.

PAULANI, Leda. Quando o Medo Vence a Esperança: um balanço da política econômica do primeiro ano do governo Lula. Crítica Marxista, no 19, p.11-26, 2006.

PIO, Carlos. Estabilização Heterodoxa no Brasil: ideias e redes políticas. Revista Brasileira de Ciências Sociais, Vol. 16, nº 46, p.31-54, 2001.

REIS, Fábio Wanderley e O’DONNELL, Guilhermo. A Democracia no Brasil: dilemas e perspectivas. São Paulo: Vértice, 1988.

SALLUM JR, Brasílio. Labirintos: dos generais à democracia. São Paulo: Hucitec, 1996.

. O Brasil sob Cardoso: neoliberalismo e desenvolvimentismo. Tempo Social: Revista de Sociologia da USP, Vol. 11, n ${ }^{\circ}$ 2, p.2347,1999 .

SARDEMBERG, Carlos Alberto. Aventura e Agonia: nos bastidores do Cruzado. São Paulo: Cia das Letras, 1987.

SINGER, André. A Segunda Alma do Partido dos Trabalhadores. Novos Estudos CEBRAP, n ${ }^{\circ} 88$, p.88-111, 2010.

SOLA, Lourdes e LOUREIRO, Maria Rita. Democracia, Mercado e Estado. Rio de Janeiro: FGV, 2011.

TOLEDO, Roberto Pompeu de. O Presidente Segundo o Sociólogo. São 
Paulo: Cia das Letras, 1998.

VIEIRA, José Ribas, BARBOSA, Livia Neves de Holanda, PRADO, Luis Carlos Delorme, LEOPOLDI, Maria Antonieta e D'ARAÚJO, Maria Celina. Na Corda Bamba: doze estudos sobre a cultura da inflação. Rio de Janeiro: Relume Dumará, 1993.

Recebido:10/08/2013

Aprovado: 19/11/2013 